\title{
EDUCAÇÃO E REVOLUÇÃO: UM ESTUDO COMPARADO ENTRE LORENZO MILANI E JOHANN HEINRICH PESTALOZZI
}

\section{EDUCATION AND REVOLUTION: A COMPARATIVE STUDY BETWEEN LORENZO MILANI AND JOHANN HEINRICH PESTALOZZI}

\author{
Roberto Ribeiro da Silva ${ }^{1}$ \\ Universidade Federal do Rio Grande do Norte - UFRN \\ Antônio Basílio Novaes Thomas de Menezes² \\ Universidade Federal do Rio Grande do Norte - UFRN
}

\begin{abstract}
Resumo
O presente artigo é um estudo comparado (SAVIANI, 2001). Materializa-se a partir da análise comparativa desenvolvida entre duas percepções educativas revolucionárias, com desdobramentos metodológicos e pedagógicos. A primeira percepção, materializada numa pequena vila da região de Florença (Itália), pelo padre Lorenzo Milani, entre os anos de 1954 a 1965, estabelece nexos com a segunda percepção, oriunda da reflexão e da prática do pedagogo e educador Johann Heinrich Pestalozzi, entre os anos de 1746 a 1827; como Milani, experienciou-se na prática a sua teoria pedagógica, dirigida às crianças pobres e excluídas, moradoras da aldeia de Stans e Iverdon (Suíça). A partir das análises, nossos resultados demonstram que tais práxis educativas denotam, pelo seu caráter visionário, dado o contexto e tempo, um caráter revolucionário, tornando-se fonte inspiradora a qualquer tempo na concepção ou na defesa de uma escola para todos.
\end{abstract}

Palavras-chave: Lorenzo Milani; Johann Heinrich Pestalozzi; Educação Revolucionária; Escola Pública.

\section{Abstract}

The present article is a study (SAVIANI, 2000). It materializes from the comparative analysis developed between two revolutionary and educative perceptions with methodological and pedagogical repercussions (developments). The first perception, materialized in small village of the region of Florence, Italy, by priest Lorenzo Milani from 1954 to 1965, stablishes nexus with a second perception, arising from the reflection and the practice of the pedagogue and educator Johann Heinrich Pestalozzi from 1746 to 1827, once Milani experienced in practice his pedagogical theory directed to the poor and excluded children, which live in Stans \& Iverdon hamlet, Switzerland. Based on the analysis, our outcomes prove that such educative praxis by its visionary characteristics, given

\footnotetext{
${ }^{1}$ Filósofo e mestre em educação pela Universidade Federal do Rio Grande do Norte - UFRN/PPGEdu. ORCID: https://orcid.org/0000-0002-7973-2276. E-mail: perobertoribeiro@hotmail.com.

2 Professor do Programa de Pós-graduação em Educação (PPGED) da Universidade Federal do Rio Grande do Norte (UFRN). ORCID: https://orcid.org/0000-0001-7841-2118. E-mail: gpfe.ufrn@gmail.com.
} 
the context and time, exhibits a revolutionary nature becoming an inspiring source at any time in the conception or in defense of a school for all.

Keywords: Lorenzo Milani; Johann Heinrich Pestalozzi; Education Revolutionary; Public school.

\section{INTRODUÇÃO}

Na manhã de 20 de junho de 2017, olhando as várias notícias trazidas ao mundo pelo pontificado 'reparador' do Papa Francisco ${ }^{3}$, encontramos um noticiário de sua visita a um vilarejo chamado Barbiana, uma pequenina localidade da região rural de Florença, na Itália, onde atuou como pároco o padre Lorenzo Milani (1923-1967). Constatamos que o padre Milani representa uma figura proeminentemente controversa da igreja católica italiana, nos anos pré-conciliares e posteriores ao Concílio Vaticano II $^{4}$.

No Jardim adjacente à Igreja de Santo André na Barbiana (Florença), o Papa Francisco, discursando, ao recordar Lorenzo Milani, afirmou,

[...] alegro-me por me encontrar aqui com quantos outrora foram alunos do padre Lorenzo Milani, [...] sois testemunhas da sua paixão educativa, da sua intenção de despertar nas pessoas o humano para as abrir ao divino. Por isso ele se dedicou completamente à escola, com uma opção que aqui em Barbiana pôs em prática de modo ainda mais radical. A escola, para o padre Lorenzo, não era uma coisa diversa da sua missão de sacerdote, mas o modo concreto de desempenhar aquela missão, dando-lhe um fundamento sólido e capaz de elevar até ao céu. E quando a decisão do Bispo o deslocou de Calenzano para cá, entre os jovens de Barbiana, compreendeu imediatamente que se o Senhor tinha permitido aquele afastamento era para Ihe dar novos filhos para fazer crescer e amar. Restituir a palavra aos pobres, porque sem a palavra não há dignidade e por conseguinte nem sequer liberdade e justiça: eis quanto ensina o padre Milani. E é a palavra que poderá abrir o caminho para a plena cidadania na sociedade, mediante o trabalho, e a pertença plena à Igreja, com uma fé consciente. Isto é válido à sua maneira também para o nosso tempo, no qual possuir unicamente a palavra pode permitir o discernimento das tantas e muitas vezes confusas mensagens que chovem em cima de nós, e dar expressão às instâncias profundas do próprio coração, assim como às expetativas de justiça de tantos irmãos e irmãs que esperam justiça. Daquela humanização que reivindicamos para cada pessoa nesta terra, juntamente com o pão, a casa, o trabalho, a família, faz parte também a posse da palavra como instrumento

3 Jorge Mario Bergoglio (Papa Francisco), nascido em Buenos Aires - Argentina, em 17 de dezembro de 1936. Primeiro papa jesuíta, entre os 265 que o antecederam no Vaticano, é o primeiro papa latino-americano. Tornou-se arcebispo de Buenos Aires em 28 de fevereiro de 1998, elevado ao cardinalato em 21 de fevereiro de 2001 e eleito papa em 13 de março de 2013.

4 O Concílio Vaticano II foi anunciado já como uma intenção pelo papa João XXIII (Angelo Giuseppe Roncalli) em 25 de janeiro de1959, o que surpreendeu a todos, devido a sua idade avançada e sendo reconhecidamente escolhido como um 'papa de transição'. Só foi definitivamente convocado em 25 de dezembro de 1961, através da bula papal Humanae salutis. A necessidade de diálogo da lgreja com o mundo moderno num contexto de guerras e de grandes mudanças sociais ocorridas nos séculos XIX e XX foram alguns dos principais motivos para a convocação do Concílio. Seu encerramento se deu apenas em 08 de dezembro de1965, já no pontificado do papa Paulo VI (Giovanni Battista Enrico Antonio Maria Montini). 
de liberdade e de fraternidade. [...] os educadores, a quantos se põem ao serviço do crescimento das novas gerações, em particular dos que estão em situações de dificuldade. A vossa é uma missão de amor, porque não se pode ensinar sem amar e sem a consciência de que aquilo que se doa é apenas um direito que se reconhece, o de aprender. $E$ há tantas coisas para ensinar, mas a essencial é o crescimento de uma consciência livre, capaz de se confrontar com a realidade e de se orientar nela guiados pelo amor, pela vontade de se comprometer com os outros, de se encarregar das suas canseiras e feridas, de evitar qualquer egoísmo para servir o bem comum. Encontramos escrito na Carta a uma professora: «Aprendi que o problema dos outros é igual ao meu. Libertar-se dele todos juntos é política. Libertarse dele sozinhos é avareza». Este é um apelo à responsabilidade. Um apelo que diz respeito a vós, queridos jovens, mas antes de tudo a todos nós, adultos, chamados a viver a liberdade de consciência de modo autêntico, como busca do verdadeiro, do belo e do bom, prontos a pagar o preço que isto exigir. E sem compromissos. (FRANCISCO, 2017).

Ao investigarmos a vida de Lorenzo Milani, motivados pela visita papal, logo percebemos, em meio às nossas pesquisas, as fortes vivências de aberturas trazidas à sua identidade na década de 1960, a maioria delas provindas do mundo eclesial marcado pelo revolucionário pontificado de João XXIII. Já em fevereiro de 1965, no final do Concílio Vaticano II, um fato bastante relevante a caracterizar sua personalidade, quando na Toscana alguns capelães da reserva Militar divulgaram à imprensa carta acusando de covardes os jovens italianos objetores de consciência. Milani os defendeu publicamente, exigindo que os capelães respeitassem os jovens que tinham sido presos pelo ideal da nãoviolência. Seu falecimento precoce aos 44 anos não impediu que deixasse na obra 'Carta a uma professora', construída numa escrita em mutirão com os jovens da escola de Barbiana, um legado profundo de pedagogo e educador revolucionário de grande originalidade.

Imagem 1 - Lorenzo Milani e as crianças em Barbiana

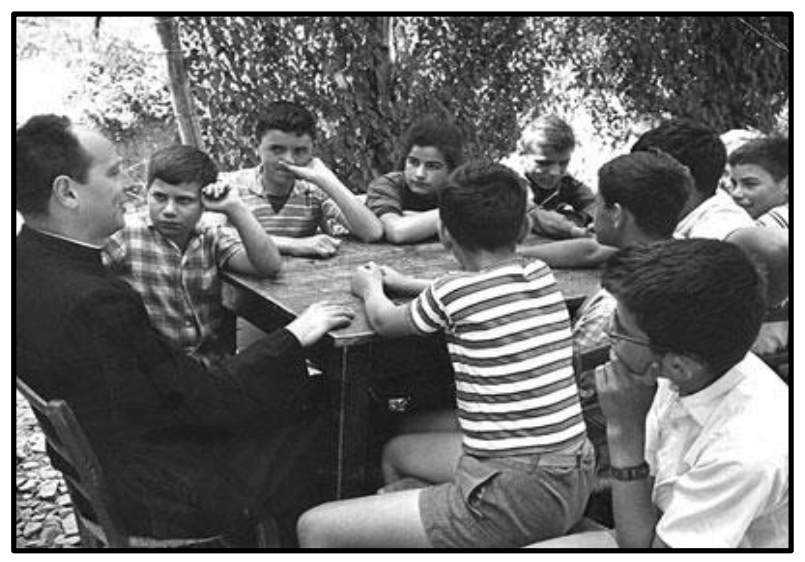

Fonte: Site da Fondazione Don Lorenzo Milani ${ }^{5}$

${ }^{5}$ Disponível em: <https://www.donlorenzomilani.it> acesso em 10 de fevereiro de 2019. 
Em sua práxis educacional, Milani deixa latente a preferência pelos pobres e a defesa pela escola pública emancipadora. No Brasil, encontramos sua grande proximidade com as teorizações de Paulo Freire, na dedicação contínua aos oprimidos e desfavorecidos,

[...] a educação que se impõe aos que verdadeiramente se comprometem com a libertação não pode fundar-se numa compreensão dos homens como seres "vazios" a quem o mundo "encha" de conteúdos; não pode basear-se numa consciência especializada, mecanicistamente compartimentada, mas nos homens com "corpos conscientes" e na consciência intencionada ao mundo. (FREIRE, 1978, p. 37)

Paulo Freire, um dos mais importantes pedagogos da abordagem da pedagogia crítica, poderia ter conhecido a obra de Milani, segundo as teorizações de Batini

[...] é, no entanto, plausível que Paulo Freire tenha sido exposto ao nome e legado de Dom Milani e da Escola de Barbiana durante o tempo em que ele trabalhou em Genebra para o Conselho Mundial de Igrejas. É possível, embora não encontremos praticamente nenhuma referência em seu trabalho amplamente publicado em inglês, que Freire tenha se deparado com tal legado durante seus encontros com os trabalhadores italianos, sindicalistas e educadores na Suíça e na Itália. (BATINI, 2016, p.109).

A história em muitos cenários representa um retorno cíclico de acontecimentos. Como em Barbiana, numa velha edificação de um antigo convento feminino, Johann Heinrich Pestalozzi (1746-1827), pedagogo e educador popular, desenvolveu semelhante obra educadora que sempre nos despertou admiração pelo seu caráter visionário, com acentos advindos das ideias iluministas.

Ele materializou uma concepção de educação escolar integral, observando a própria existência da criança e suas necessidades diárias na vida comunitária, como fizera Milani em Barbiana com as crianças que na linguagem da carta chama de "os Gianni reprovados".

Como pilar norteador para a sua ação pedagógica direcionada às crianças pobres da aldeia sueca de Stans e Iverdon, defendeu "[...] a ideia de não se recorrer a nenhum recurso artificial, de se usar apenas como recurso educativo a natureza à volta da criança, as necessidades diárias e sua atividade, sempre animada" (INCONTRI, 1996, p. 143 - 144).

Imagem 2 - Pestalozzi na sua escola 


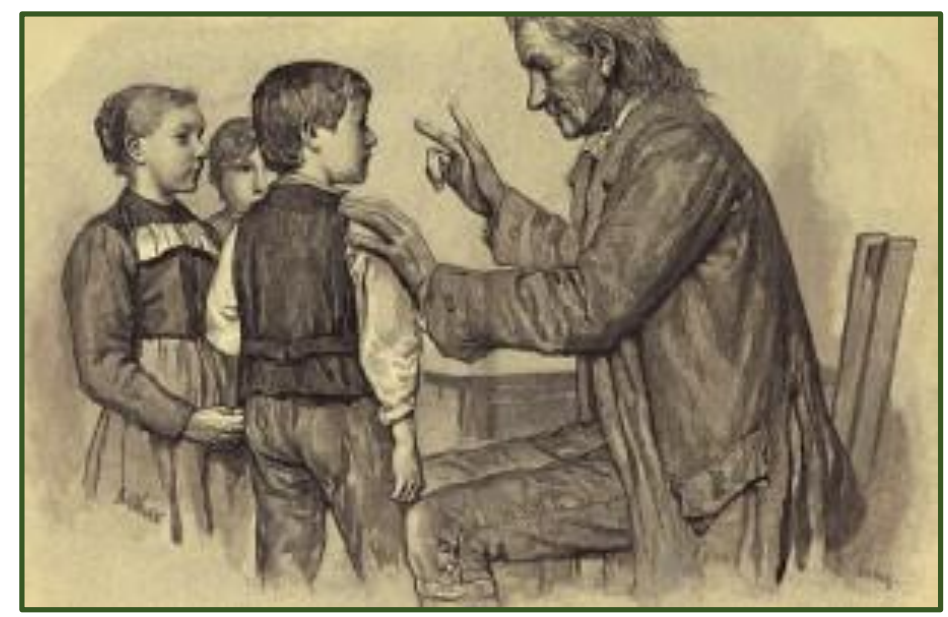

Fonte: Site PGL.gal ${ }^{6}$

Desse cenário originado no encontro desses dois educadores, surgiu nosso interesse de contribuir no campo educacional, pretendendo atualizar com este estudo comparado as proposições pedagógicas potencialmente renovadoras, fazendo convergir nas proximidades das abordagens metodológicas e conceituais uma redescoberta de métodos educacionais plasmados em prol daqueles tidos como fracassados da escola regular, em vista da transformação social por meio da educação.

Esse estudo comparativo vem sublinhar o aspecto da radicalidade dos dois educadores: Milani e Pestalozzi. No resgate análogo das práticas educativas libertadoras desenvolvidas em contextos distintos, mas que se entrelaçam em similaridades, principalmente quando analisados comparativamente, torna-se possível encontrar em comum entre esses dois pedagogos um pensar educativo a respeito da escola para todos, integral e como responsabilidade social.

Para desenvolver o presente estudo como contribuição à história da educação comparada, elegemos Demerval Saviani, ao teorizar que,

[...] a história da educação comparada se insere naquilo que hoje vem sendo denominado de história das disciplinas. Trata-se, nesse caso, de se investigar a trajetória da educação comparada desde suas origens até os dias atuais. Ao que parece, este é um campo ainda inexplorado à espera de alguém que se disponha a levantar, organizar, analisar e criticar as fontes disponíveis, sistematizando os resultados alcançados. (SAVIANI, 2001, p.9)

Para melhor compreensão, o estudo foi desenvolvido por meio de uma revisão de literatura, conforme Luna (2002). Adentraremos metodicamente as discursões teóricas de Milani e Pestalozzi, objetivando alcançar comparativamente os intercâmbios entre esses dois educadores. Como agiu Milani, sem subestimar a inteligência das crianças e dos

\footnotetext{
${ }^{6}$ Disponível em: <https://pgl.gal/pestalozzi-o-educador-da-humanidade-documentario-da-serie-grandes-educadores/> acesso em 10 de fevereiro de 2019.
} 
jovens criando um método no qual havia a troca de conhecimentos entre uns e outros, comparativamente, Pestalozzi, um educador apaixonado por uma visão de escola para todos, também aliou a sua práxis pedagógica ao desejo de tornar as suas crianças e jovens alunos ativos, atentos, dispostos e obedientes para com as atitudes exteriores. Assim como Milani, Pestalozzi desenvolve um sistema de ensino mútuo, num processo dialógico em que as crianças mais talentosas ensinavamas crianças menores.

Nesse sentido, o presente estudo coopera para incluir tais ideias pedagógicas no elenco de métodos educativos preeminentemente revolucionários na história da educação, dentro de uma mesma perspectiva de análise em pesquisas posteriores, para 0 entrelaçamento das proximidades que um estudo comparativo possa desenvolver com base no contributo aos pesquisadores e à história da educação, como constatamos nas teorizações de Demerval Saviani,

[...] considero essa linha de investigação de grande relevância e, mesmo, uma condição para se colocar, de forma mais precisa, a questão da viabilidade, alcances e limites dos estudos de história comparada da educação entre o Brasil e os outros países. Com efeito, é a partir daí que será possível distinguir entre o que é próprio da educação brasileira como um todo e aquilo que é específico de cada uma das diferentes regiões que compõem o nosso país. (SAVIANI, 2001, p. 14).

Nesse sentido, o presente estudo encontra sua atualidade e importância no auxílio e desenvolvimento de pesquisas inovadoras no campo da história da educação.

\section{O ENCONTRO DAS ABORDAGENS PEDAGÓGICAS DE MILANI E PESTALOZZI: A DEFESA DA ESCOLA INTEGRAL PARA TODOS E A LUTA POR JUSTIÇA SOCIAL}

Ao desenvolver a pesquisa sobre a experiência educativa de Milani, deparamo-nos com uma expressão lapidar na obra 'Carta a uma professora pelos rapazes de barbiana', que só ela, bem como todo o intento do presente trabalho, suficientemente consegue circunscrever o objetivo desse educador: "[...] nós estamos em busca de um objetivo. Precisa ser um objetivo honesto. Um grande objetivo. O que se quer do aluno é que ele não seja nada menos que um ser humano" (CARTA, p. 14, 1967).

Os autores da obra são os alunos da escola de Barbiana, onde seus testemunhos servem de alerta contra o sistema educacional, ao passo que, pelo peso reflexivo, obriga a prática educativa a se revisitar criticamente.

Gianni, ao longo do texto, é constituído como o aluno exemplo da exclusão impetrada pelo sistema educacional, é posto em paralelo com outro aluno chamado de Pierino, o filho do doutor. 
Nesse paradoxo desenrola-se uma crítica à escola que exclui,

\section{[...] Senhora Professora,}

Julgo que já nem se lembra do meu nome e é natural; não foi só a mim que a senhora professora chumbou, foram centenas... Cá por mim pensei muitas vezes na senhora professora, nos seus colegas, nessa instituição a que chamam ensino, em todos os miúdos que os professores <<chumbam $>>$. Chumbam-nos, mandam-nos para os campos ou para a fábrica e depois esquecem-se de nós. (CARTA, p. 11,1967).

Já na primeira parte do livro deparamo-nos com uma temática paradoxal: 'A escola obrigatória não tem o direito de reprovar', referindo-se aos campesinos e sua relação com a escola como um processo contínuo de exclusão, os jovens de Barbiana denunciam a indiferença dada a essa situação:

Por exemplo, aprendi que o problema dos outros é igual ao meu. A política é a gente conseguir fazer as coisas todos juntos, a avareza é fazê-las sozinhos [...] a senhora professora dirá que estas coisas não são nada do outro mundo. Mas o que é certo é que não faz o mesmo pelos seus alunos. Nunca lhes pede nada. Ou melhor, pede-lhes; manda-os fazer sozinhos o caminho deles. (CARTA, p. 17, 1967).

Essa exclusão desenrola-se por meio de uma crítica quanto a ação educativa se descuidar por uma linguagem adequada e imprimir exames que são denominados 'chumbos', para promover a repetência e sistemáticos abandonos aos chumbados do sistema escolar. As propostas e alternativas sugeridas na obra são: primeiramente, 'não haver mais chumbos', nessa expressão se vincula enfaticamente a de que a escola que reprova não é digna deste nome.

Outra alternativa é o denominado 'tempo inteiro', uma proposta de escola em tempo integral e com um percurso bastante delineado na obra.

Tal abordagem comunica-se teoricamente com a perspectiva educacional de Pestalozzi, com quem comparativamente desenvolvemos o presente estudo; ele defendia que, para que uma experiência educativa seja considerada popular e tenha eficácia, deve atingir, segundo Pestalozzi (1996, p. 140), “[...] um número apreciável das crianças mais pobres, dando-Ihes educação completa, se essas crianças não fossem retiradas do seu meio, mas se tornassem, ao contrário, por meio da educação, muito mais atadas a ele".

Pestalozzi assume destaque enquanto pensador da educação, com características bastante singulares, conforme teoriza Kreimendahl,

[...] pedagogos como Basedow e Pestalozzi insistem na educação do indivíduo isso ocorre porque o olho pedagógico direciona-se à questão de saber se a espécie é educável ou não. Lessing percebe a História como 
sendo a educação da espécie humana na busca por uma moralidade autônoma. Também Schiller quer lapidar a moral do ser humano, mas ele não aposta no imperceptível passo da providência, ele mesmo assume e acredita no desenvolvimento da moralidade por meio do caminho indireto da educação estética do ser humano (KREIMENDAHL, 2004, p. 34-35).

Ao investigar a educação das crianças no século XVIII, encontramos destacada na história a contribuição de Johann Heinrich Pestalozzi. Mesmo conservando a família no centro da ação educadora como possibilitadora do surgimento das demais instituições sociais, reconhece que a educação das crianças não se encerra no ambiente familiar, há necessidade de uma escola. Sua proposta educacional, tendo como base a experiência, foi inspiradora de uma escola voltada para as classes populares e herdeira de uma abordagem em prol do social. Segundo as teorizações de Luzuriaga, em Pestalozzi a formação religiosa da criança, que deveria ser apreendida, sobretudo, pela via do sentimento,

[...] reconhece constantemente o valor da educação religiosa; só que, para ele, sem caráter dogmático e confessional: sua religiosidade é antes amor, aspiração ao aperfeiçoamento, que submissão a seita ou dogma. por isso, quase não é suscetível de ensino. (LUZURIAGA, 2001, p. 175).

O pensamento e a vida de Pestalozzi vinculam-se naturalmente à instituição escolar, a educação das crianças é a materialização do seu agir como um vocacionado para o serviço ao próximo, quase comparável ao sacerdócio de Milani.

Segundo Luzuriaga, quando Pestalozzi, aos vinte e cinco anos de idade, comprou uma granja chamada Neuhof, devendo fechá-la uns anos depois por não saber administrála, tem início sua ação educativa,

[...] nela começa sua primeira experiência educacional, ao converter a granja num estabelecimento para educação de meninos pobres, que trabalhavam ao mesmo tempo que se educavam, tornando-a, dessa forma, verdadeira escola ativa ou do trabalho. (LUZURIAGA, 2001, p. 174)

As ideias educacionais de Pestalozzi o constituíram como um precursor do pensamento pedagógico contemporâneo; ele seguiu o caminho da experiência para desenvolver seu método educativo, conforme teoriza Cabanas,

Primero hace y observa, luego pondera y critica, y por último escribe. Repetidas veces en el presente libro afirma que apoya en esta base empírica todas sus conclusiones, con la conciencia de que, por tal motivo, son irrebatibles; y tanto el tiempo como el actual espíritu científico, que impera también en los dominios pedagógicos, han demostrado que se hallaba en lo cierto. La pedagogía de Pestalozzi es fruto de la observación y la experimentación, lo cual no excluye, por supuesto, sino que implica un grado nada común de genial intuición sobre la naturaleza del niño y del proceso educativo. (CABANAS, apud PESTALOZZI, 1996, p.12). 
A concepção educativa de Pestalozzi considerava a totalidade da vida familiar e comunitária, como bem empregou semelhante ação Milani, em Barbiana. E assim, ir cultivando na prática os sentimentos da vida em comum para o bem social e, ao mesmo tempo, desenvolver equilibradamente suas primeiras faculdades, habilidades, sentimentos (justiça e solidariedade), noções civis (direito e deveres) e exercícios de autodomínio, para imediata aplicação nas condutas diárias.

Durante muito tempo não se viu em Pestalozzi mais que o criador e organizador de métodos de ensino. Depois, negou-se a eficiência deles, considerados então como algo mecânico e, automático. Hoje, entretanto, acabou-se por dar-Ihe a verdadeira significação de auxiliares e instrumentos do mestre, que pode alterá-los segundo as condições psíquicas do aluno e as circunstâncias do momento, continuando em pé as linhas essenciais, 0 arcabouço do método. (LUZURIAGA, 2001, p. 177).

A educação escolar em tempo integral das classes populares é manifesta como construção mútua da totalidade das relações sociais. A pedagogia pestalozziana é indiscutivelmente de grande relevância, seu contributo transcende marcos históricos por isso nomeamos sua ação pedagógica de revolucionária. Mesmo com os condicionantes do momento histórico, no campo da educação ele arregimentou modos espaciais e metodológicos, a fim de tornar possível um ensino voltado para a instrução das crianças, assegurando-Ihes o conhecimento. O pensamento de Pestalozzi sobre a educação escolar para criança das classes populares se atualiza em nossos tempos como um chamado à luta de todos educadores por uma escola pública de qualidade para todos.

\section{CONSIDERAÇÕES FINAIS}

Milani, em suas práticas educacionais que se descortinam na obra 'Carta a uma professora pelos rapazes da escola de Barbiana', legou a defesa de uma escola comprometida com o educando, não só na concepção conceitual, mas também em aspectos sociais por uma educação emancipadora.

Por sua vez, Pestalozzi defende uma convicção acerca da educação escolar das classes populares, luta por uma educação integral que forme o coração, a cabeça e a mão. A educação escolarizada é um complemento da educação familiar e uma preparação para a educação conferida pela vida, portanto, edificada sobre a totalidade viva, considerando as relações familiares em toda sua extensão humana e social.

A relevância de um estudo comparativo se faz necessária pela riqueza de elementos e categorias conceituais de análises aos pesquisadores no campo educacional, mais especificamente, ligados à história da educação. 
Nesse sentido que o desejo por uma educação revolucionária como as desenvolvidas por Milani e Pestalozzi atualiza-se aos educadores comprometidos com uma educação para todos em nosso país, velando para que os jovens escolarizados no Brasil tenham respeitados os direitos de acessar conteúdos responsáveis pelo desenvolvimento de uma consciência crítica em vista do pleno exercício da cidadania.

Compreendemos ser oportuno tecer nexos entre as propostas por Milani e Pestalozzi, e acima descritas, para estabelecer uma crítica à realidade brasileira atual no campo educacional, principalmente no que se refere ao direito dos jovens escolarizados em acessar conteúdos como os que compõem a disciplina de Filosofia.

Com a atual reforma do Ensino Médio brasileiro, proposta pelo governo Michel Temer (2016) e transformada na Lei 13. 415/17, marcando a retomada do enfoque tecnicista que privilegia o empresariado pela formação de mão-de-obra barata, a partir do baseamento em políticas educacionais internacionais com padrões capitalistas.

A consequência disso é o reposicionamento curricular da Filosofia, mais uma vez, na história do Ensino Médio brasileiro. A Filosofia é agora subjugada e camuflada intencionalmente, passando a figurar como disciplina optativa, relegada mais uma vez a um quadro de esquecimento dentro do currículo.

O que voltamos a experimentar atualmente, semelhante ao tempo da ditadura CivilMilitar, a respeito da perda da obrigatoriedade da disciplina de Filosofia, e o desdobramento reeditado mais uma vez é que a Filosofia foi golpeada dentro do currículo secundário, repetindo a saga imposta ao seu ensino no Brasil. Atitudes como estas enfraqueceram o debate sobre a concepção e finalidade da Filosofia, o que pode ter permitido uma antipatia ao seu lugar no currículo e negação da sua importância e contributo como disciplina no Ensino Médio brasileiro. O atual presidente da república demonstrou que tal compreensão não compõe sua plataforma de governo para a educação, as ciências humanas para ele não teriam resultado imediato, Filosofia e Sociologia seriam artigo de luxo para quem pudesse pagar.

A política educacional de Estado que abre mão da Filosofia em caráter obrigatório é desdobramento do processo de ruptura democrática que experimentamos no Brasil na atualidade, com grandes interesses hegemônicos, resultado de um recrudescimento da ideologia dominante.

Tal problemática em curso, à luz da perspectiva crítica desenvolvida com base no agir e no pensar de Milani e Pestalozzi, reinaugura uma renovada preocupação de enfrentamento aos interesses antagônicos com o futuro dos jovens escolarizados no Ensino 
Médio brasileiro, devido ao sentimento de que estará sendo retirada a disciplina obrigatória que maior contributo daria ao futuro incerto do regime democrático a agonizar.

A retomada do debate sobre o ensino de Filosofia no Ensino Médio brasileiro reaparece agora com efetividade devido a sua perda de obrigatoriedade no currículo como disciplina. Além do medo que ela seja engolida pela abordagem técnica, hoje se pergunta sobre o destino da Filosofia na relação com a escola, compreendida aqui como o espaço que porta em uma dimensão pública quando comparada a família, que tem um aspecto privado em relação a ação educativa.

Diante de uma educação que vive dias confusos sobre o que será legado às novas gerações, da fragmentação do ensino da Filosofia fornecida pela "nova" estrutura curricular da base comum nacional para o ensino médio, nosso objeto de pesquisa pretende demonstrar a importância da disciplina de Filosofia para a emancipação cidadã dos alunos do Ensino Médio brasileiro, a partir do aceno metodológico do diálogo plural na escola com suas consequências pedagógicas como meio de superação da distância que possa haver entre professores e alunos, e despertar a assumida da educação para a cidadania.

A essencialidade disciplinar da Filosofia no Ensino Médio se configura em proporcionar aos educandos a capacidade analítica sobre a história e a uma investigação sobre contextos distintos à luz dos contributos filosóficos de forma crítica e autônoma, gerando condições para o exercício do pensar e do agir, como resposta às indagações contemporâneas.

No currículo escolar a Filosofia coopera com as demais disciplinas do Ensino Médio para a leitura e compreensão dos desafiantes contextos apresentados aos indivíduos, recebe relevante papel na orientação da consciência em vista do desenvolvimento crítico e do exercício da sua autonomia, como instrumental necessário na reconstrução dos ideários desafiantes presentes na sociedade a qual se insere.

A Filosofia não é uma elucubração criativa de aferro intelectual ou pura abstração de gênio racional sem conexão com a vida. Defendemos a Filosofia como a consubstanciação de artifícios humanos, materializada na forma de sentido, de pensamento e de ação, que traduz o próprio ser humano.

As determinações atuais da reforma educacional excluíram conteúdos obrigatórios como os pertencentes à disciplina de Filosofia do currículo escolar. Essa medida, configurada na BNCC a ser efetivada nas escolas, porta uma unilateralidade sem precedentes na história recente do país, representando uma quebra de diálogo com os educadores e pensadores da educação. 
Após a análise do entroncamento legal patrocinado pelo governo Michel Temer, deduzimos que é verdadeiro pensar o que muitos teóricos da educação teorizam a respeito do currículo escolar, como um espaço intercruzado por redes de interesses e disputas pela hegemonia ideológica dentro da agenda do poder regulador, tencionando para 0 aparelhamento estatal cujo fim último será sempre o lucro. Afirmamos, por causa disso mesmo, que o currículo escolar não é uma interposição ingênua ou positiva de conteúdos sistematizados de forma altruísta, muito pelo contrário, obedecem a interesses de pauta das classes hegemônicas.

A exclusão curricular da Filosofia como disciplina obrigatória deve-se possivelmente por ela cooperar para desenvolver a capacidade geradora de raciocínios críticos nos educandos, elucidar pontos de vista e fomentar uma maneira própria de pensar, que é geradora de autonomia.

Esse modo de percebê-la no ambiente escolar não é evidentemente compactuado por quem ideologicamente anseia à dominação social e faz da regulação educacional o instrumento de manipulação. A permanência e a exclusão da Filosofia como disciplina escolar, ou mesmo a elaboração de princípios adotados na disposição curricular, abriga fortes embates ideológicos dos que tencionam interesses hegemônicos e enxergam, associados ao seu ensino, um elemento destoante a tal ideário massificante.

A Filosofia ensinada aos jovens escolarizados no Ensino Médio brasileiro constituise como uma ameaça aos interesses mercadológicos da classe dos empresários, que por sua vez são os financiadores da classe política, objetivando extensivamente a um aparelhamento do Estado com controles multifacetados, comprometendo o acesso às novas gerações de uma educação emancipadora como transmissão cidadã do mundocomum.

É fato que a formação cidadã não fica circunscrito dentro do currículo escolar somente como tarefa da disciplina de Filosofia. A formação para a cidadania aos mais jovens é defendida no campo educacional como um tema transversal.

Milani e Pestalozzi, em seu fazer pedagógico, frente ao atual cenário, representam um estímulo na luta pela escola capaz de formar para a vida.

\section{REFERÊNCIAS}

BATINI, Federico. Lorenzo Milani: a escola de Barbiana e a luta por justiça social. Tradução: André Cechinel, Rafael Rodrigo Mueller. - Criciúma: Ediunesc; Florianópolis: Ed. da UFSC, 2016. 
CARTA A UMA PROFESSORA. 4. ㄹ ed. Lisboa: Editorial Presença, 1967.

FRANCISCO, Papa. Visita ao túmulo do padre Lorenzo Milani. Disponível em:<< https://w2.vatican.va/content/francesco/pt/speeches/2017/june/documents/papa-

francesco 20170620 don-lorenzo-milani.html >>. Acesso em 10 de agosto de 2018.

FREIRE, Paulo. Pedagogia do oprimido. 6. Ed. Rio de Janeiro: Paz e Terra, 1978.

KREIMENDAHL, L. (Org.) Filósofos do século XVIII. São Leopoldo, RS: Editora UNISINOS, 2004.

LUNA, Sergio Vasconcelos de. Planejamento de pesquisa: uma introdução. São Paulo: Ed. Educ, 2002.

LUZURIAGA, L. História da educação e da pedagogia. São Paulo: Companhia Editora Nacional, 2001.

PESTALOZZI, Johann Heinrich. Cartas de Stans. In: INCONTRI, Dora. Pestalozzi: educação e ética. São Paulo: Editora Scipione, 1996.

PESTALOZZI, Johann Heinrich. Cartas sobre educación infantil. Madrid: Tecnos, 1996.

SAVIANI, Dermeval. História Comparada da Educação: algumas aproximações: História da Educação, ISSN-e 2236-3459, Vol. 5, №. 10, 2001, págs. 5-16. Disponível em: $<$ https://dialnet.unirioja.es/servlet/articulo?codigo=4053011 > Acesso em 22 de agosto de 2018.

Artigo recebido em: 24 de julho de 2019. Aceito para publicação em: 20 de janeiro de 2020.

Manuscript received on: July 24, 2020 Accepted for publication on: January 20, 2020 